\title{
Front Matter: Volume 7146
}

, "Front Matter: Volume 7146," Proc. SPIE 7146, Geoinformatics 2008 and 'Joint Conference on GIS and Built Environment: Advanced Spatial Data Models and Analyses, 714601 (11 November 2008); doi: 10.1117/12.820481

Event: Geoinformatics 2008 and Joint Conference on GIS and Built Environment: Geo-Simulation and Virtual GIS Environments, 2008, Guangzhou, China 


\title{
PROCEEDINGS OF SPIE
}

\section{Geoinformatics 2008 and Joint Conference on GIS and Built Environment Advanced Spatial Data Models and Analyses}

\author{
Lin Liu \\ Xia Li \\ Kai Liu \\ Xinchang Zhang \\ Editors
}

\section{8-29 June 2008 \\ Guangzhou, China}

Organized by

Sun Yat-sen University (China) - University of Cincinnati (USA) - CPGIS-The International Association of Chinese Professionals in Geographic Information Sciences

\section{Co-organized by}

Guangzhou Institute of Geography (China) • South China Normal University (China) • Guangdong Institute of Eco-Environmental and Soil Sciences (China) • Guangdong Association of Remote Sensing and Geographic Information Systems (China)

Sponsored by

NSFC-National Natural Science Foundation of China

Published by

SPIE 
The papers included in this volume were part of the technical conference cited on the cover and title page. Papers were selected and subject to review by the editors and conference program committee. Some conference presentations may not be available for publication. The papers published in these proceedings reflect the work and thoughts of the authors and are published herein as submitted. The publisher is not responsible for the validity of the information or for any outcomes resulting from reliance thereon.

Please use the following format to cite material from this book:

Author(s), "Title of Paper," in Geoinformatics 2008 and Joint Conference on GIS and Built Environment: Advanced Spatial Data Models and Analyses, edited by Lin Liu, Xia Li, Kai Liu, Xinchang Zhang, Proceedings of SPIE Vol. 7146 (SPIE, Bellingham, WA, 2008) Article CID Number.

ISSN 0277-786X

ISBN 9780819473882

Published by

SPIE

P.O. Box 10, Bellingham, Washington 98227-0010 USA

Telephone +1 3606763290 (Pacific Time) · Fax +1 3606471445

SPIE.org

Copyright (C) 2008, Society of Photo-Optical Instrumentation Engineers

Copying of material in this book for internal or personal use, or for the internal or personal use of specific clients, beyond the fair use provisions granted by the U.S. Copyright Law is authorized by SPIE subject to payment of copying fees. The Transactional Reporting Service base fee for this volume is $\$ 18.00$ per article (or portion thereof), which should be paid directly to the Copyright Clearance Center (CCC), 222 Rosewood Drive, Danvers, MA 01923. Payment may also be made electronically through CCC Online at copyright.com. Other copying for republication, resale, advertising or promotion, or any form of systematic or multiple reproduction of any material in this book is prohibited except with permission in writing from the publisher. The CCC fee code is 0277-786X/08/\$18.00.

Printed in the United States of America.

Publication of record for individual papers is online in the SPIE Digital Library.

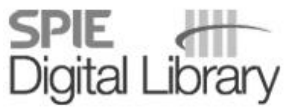

SPIEDigitalLibrary.org

Paper Numbering: Proceedings of SPIE follow an e-First publication model, with papers published first online and then in print and on CD-ROM. Papers are published as they are submitted and meet publication criteria. A unique, consistent, permanent citation identifier (CID) number is assigned to each article at the time of the first publication. Utilization of CIDs allows articles to be fully citable as soon they are published online, and connects the same identifier to all online, print, and electronic versions of the publication. SPIE uses a six-digit CID article numbering system in which:

- The first four digits correspond to the SPIE volume number.

- The last two digits indicate publication order within the volume using a Base 36 numbering system employing both numerals and letters. These two-number sets start with 00, 01, 02, 03, 04, $05,06,07,08,09,0 A, 0 B \ldots 0 Z$, followed by 10-1Z, 20-2Z, etc.

The CID number appears on each page of the manuscript. The complete citation is used on the first page, and an abbreviated version on subsequent pages. Numbers in the index correspond to the last two digits of the six-digit CID number. 


\section{Contents}

\section{Part One}

$\begin{aligned} \text { xiii } & \text { Symposium Committees } \\ \text { xvii } & \text { Introduction }\end{aligned}$

SPATIAL RELATIONS AND SPATIAL-TEMPORAL DATABASES

714602 Topological spatial relation calculation in constrained Delaunay triangulation: an algebraic method [7146-01]

J. Li, Kunming Univ. of Science and Technology (China) and National Geomatics Ctr. of China (China); C. Wang, Yuxi Normal Univ. (China) and National Geomatics Ctr. of China (China); L. Ma, H. Chen, Wuhan Univ. (China) and National Geomatics Ctr. of China (China); D. Yang, X. Wu, Kunming Univ. of Science and Technology (China)

714603 SHG-Tree: an efficient granularity-based spatial index structure [7146-02]

Y. Liu, Chengdu Univ. of Information Technology (China) and Sichuan Univ. (China); Y. Liu, K. Xu, Sichuan Univ. (China); T. Zeng, Tianjin Normal Univ. (China); J. Zheng, Chengdu Univ. of Information Technology (China)

714604 Development of the updated system of city underground pipelines based on Visual Studio [7146-03]

J. Zhang, Y. Zhu, Henan Polytechnic Univ. (China); X. Li, Henan Polytechnic Univ. (China) and Zhongwei Surveying and Planning Information Engineering Co. Ltd. (China)

714605 A Schema-matching-based approach to propagating updates between heterogeneous spatial databases [7146-04]

Y. Wang, F. Wei, Henan Polytechnic Univ. (China)

714606 Design and construction of Spatial Decision Support System database based on metadata [7146-05]

W. Huang, H. Liu, Q. Luan, Beijing Normal Univ. (China), State Key Lab. of Remote Sensing Science (China), and Beijing Key Lab. of Environmental Remote Sensing and Digital City (China); J. Liu, H. Liu, Beijing Research Ctr. of Agriculture and Economics (China)

714607 A new index structure for global geospatial data [7146-06]

J. Ben, Information Engineering Univ. (China) and State Key Lab. of Resource and Environmental Information System (China); X. Tong, Y. Zhang, Information Engineering Univ. (China)

714608 Formal description of topological relations between spatial objects with a hole [7146-07] S. Zou, China Univ. of Mining and Technology (China) and East China Institute of Technology (China); B. Liu, D. Li, J. Ruan, X. Guo, East China Institute of Technology (China)

714609 A reasoning method of spatial relations on the spherical digital space [7146-08] X. Zhao, China Univ. of Mining and Technology (China); M. Hou, Beijing Institute of Civil Engineering and Architecture (China); W. Sun, Z. Yan, China Univ. of Mining and Technology (China) 
7146 OA An application of temporal-GIS in displaying geospatial polygon [7146-09]

X. Li, East China Normal Univ. (China); Z. Guo, J. Wu, East China Normal Univ. (China) and Key Lab. of Geographic Information Science, Ministry of Education (China); X. Gu, Key Lab. of Geographic Information Science, East China Normal Univ. (China)

7146 OB DOM database based on ArcSDE [7146-10]

W. Wu, Y. Bing, Liaoning Technical Univ. (China)

7146 OC A model of spatial data interoperability on Oracle Spatial [7146-11]

Q. Zhao, Wuhan Univ. (China); Q. Huang, Tsinghua Univ. (China); J. Guo, R. Wen, Wuhan Univ. (China)

7146 OD VGEs-oriented multi-sourced heterogeneous spatial data integration [7146-12] H. Su, Y. Wen, M. Chen, H. Tao, J. Shen, Nanjing Normal Univ. (China)

7146 OE Study on framework of GIS-based model metadata [7146-13]

G. Xie, J. Xie, South China Agricultural Univ. (China); H. Yu, Shanghai City Development Research and Information Ctr. (China)

7146 OF Research on triangle subdivision and cell search based on equilateral octahedron [7146-14] S. Zhang, J. Wu, J. Gan, East China Normal Univ. (China)

7146 OG Workflow-based system design for the online inspection of spatial data [7146-15] L. Chai, L. Zhang, State Key Lab. of Remote Sensing Science (China) and Beijing Normal Univ. (China); G. Yu, China Earthquake Administration (China); Y. Qu, K. Du, State Key Lab. of Remote Sensing Science (China) and Beijing Normal Univ. (China)

$7146 \mathrm{OH}$ Spatial data interoperability among multi-clients based on shared database [7146-16] M. Huang, Wuhan Univ. (China) and Geomatics Ctr. of Fujian Province (China); P. Hu, L. Xia, K. Wang, Wuhan Univ. (China)

714601 Study of spatio-temporal data model in parcel-alteration and tracing of history [7146-17] L. Gong, X. Zhang, Sun Yat-Sen Univ. (China)

7146 0J The hexagonal discrete global grid system appropriate for remote sensing spatial data [7146-18]

X. Tong, J. Ben, Z. Qing, Y. Zhang, Institute of Surveying and Mapping (China)

7146 OK A formal model describing topological relations between spatial linear objects in GIS-T [7146-19]

S. Zhang, Y. Li, Southwest Jiao tong Univ. (China)

$7146 \mathrm{OL}$ On defining structured geometry types in PostgreSQL to implement a spatial database [7146-20]

Q. Huang, Y. Gao, X. Wu, Peking Univ. (China)

$71460 \mathrm{M}$ Ontology-based geographic information semantic metadata integration [7146-21]

Q. Zhan, D. Li, X. Zhang, Y. Xia, Wuhan Univ. (China) 
7146 ON Design of an extended qualitative cardinal direction relation model based on ontology [7146-22]

H. Cao, Shaanxi Normal Univ. (China); X. Wang, Univ. of Calgary (Canada); J. Chen, National Geomatics Ctr. of China (China)

714600 A bitmap index technology adapt to original TM/ETM+ image database [7146-23]

J. LU, Wuhan Univ. (China); X. Chen, Wuhan Univ. (China) and Jiangxi Normal Univ. (China);

B. Chen, Y. Sun, Wuhan Univ. (China)

7146 OP Spatio-temporal data revision: a review [7146-24]

X. Deng, H. WU, D. Li, Wuhan Univ. (China)

$71460 Q$ Schema integration of heterogeneous geospatial database [7146-25]

K. Su, X. Zhu, Wuhan Univ. (China); F. Kong, Yang-En Univ. (China)

7146 OR Approach to the side-scan sonar data storage based on spatial database technology [7146-26]

T. Liu, R. Liu, T. Yin, N. Liu, Zhejiang Univ. (China)

7146 OS A spatial indexing system for visualizing database [7146-27]

J. Ma, Y. Li, X. Dong, South China Normal Univ. (China)

7146 OT Study on spatio-temporal data model of forest resource [7146-28]

K. Xia, Zhejiang Forestry College (China); W. Li, Zhejiang Univ. of Technology (China); P. Gao, Wuhan Ordnance N.C.O. Academy of PLA (China)

7146 OU Spatial and temporal dynamic analysis of wetland in Pearl River Estuary during 1988-2004 [7146-29]

K. Liu, Guangzhou Institute of Geography (China); B. Ai, S. Wang, Sun Yat-sen Univ. (China); W. Liu, Guangzhou Institute of Geography (China)

\section{DATA QUALITY AND FUZZY LOGIC}

7146 OV Expanded Q4 quality assessment for pan-sharpened multispectral image [7146-30] Z. Wang, Z. Zhao, Institute of Remote Sensing Applications (China)

7146 OW Analysis on slope uncertainty based on different resolution level DEM: a case study [7146-31]

W. Peng, Chengdu Univ. of Technology (China) and Sichuan Normal Univ. (China); J. Zhou, Sichuan Normal Univ. (China); C. Yang, Z. He, Chengdu Univ. of Technology (China)

7146 0X Positional uncertainty of manual digitization vertex based on simulation test [7146-32] $\mathrm{H}$. Wu, Northeast Institute of Geography and Agricultural Ecology (China) and Graduate School of the Chinese Academy of Sciences (China); Z. Liu, Northeast Institute of Geography and Agricultural Ecology (China); L. Lin, Dalian Maritime Univ. (China)

7146 OY Toward an integrated data quality analysis and assessment system for HJ satellite constellation [7146-33]

X. Li, J. Hu, X. Li, L. Tang, Academy of Opto-Electronics (China) 
$71460 Z$ Primary discussion on the relationship between spatial distributions of fuzzy slope positions and soil types [7146-34]

C.-Z. Qin, Institute of Geographical Sciences and Natural Resources Research (China); A.-X. Zhu, Institute of Geographical Sciences and Natural Resources Research (China) and Univ. of Wisconsin-Madison (United States); L. Yang, Institute of Geographical Sciences and Natural Resources Research (China) and Graduate School of the Chinese Academy of Sciences (China); B.-L. Li, T. Pei, Institute of Geographical Sciences and Natural Resources Research (China)

714610 Mapping oriented geometric quality assessment for remote sensing image compression [7146-35]

L. Zhai, X. Tang, Chinese Academy of Surveying and Mapping (China); G. Zhang, Wuhan Univ. (China)

714611 Research on setting up a data quality system for topographic mapping of west China [7146-36]

P. Yang, Wuhan Univ. (China) and Chinese Academy of Surveying and Mapping (China);

$X$. Tang, Chinese Academy of Surveying and Mapping (China); Y. Cao, Liaoning Technical Univ. (China)

714612 Topological relations under uncertainty in GIS spatial data [7146-37]

J. Gao, Wuhan Univ. (China); Y. Xia, Guangzhou Dredging Corp., Ltd. (China); D. Chen, Graduate School of Wuhan Univ. (China)

714613 Entropy uncertainty of multi-dimensional random variable [7146-38]

D. Li, X. Yang, East China Institute of Technology (China); J. Gong, Wuhan Univ. (China)

714614 Research on visualization quality control of electronic map [7146-39]

C. Xie, Y. Chen, Zhengzhou Institute of Surveying and Mapping (China); W. Li, Zhengzhou Institute of Surveying and Mapping (China) and 75711 Troops (China); X. Ke, Wuhan Univ. (China) and Xi'an Research Institute of Surveying and Mapping (China)

714615 Stereo image pair's construction and accuracy analysis based on MMT soft-baseline [7146-40]

J. Ou, J. Zhang, B. Cao, F. Bao, W. Wang, Tongji Univ. (China)

714616 Uncertainty research of remote sensing image classification based on hybrid entropy evaluation model [7146-41]

Z. Lan, Y. Liu, X. Tang, Wuhan Univ. (China) and Key Lab. of Geographic Information Systems, Ministry of Education (China); G. Liu, Wuhan Univ. (China)

714617 A survey on fuzzy theory applied in geographic information system [7146-42] F. Wu, Institute of Remote Sensing Applications (China) and Graduate Univ. of Chinese Academy of Sciences (China); W. Cui, Institute of Remote Sensing Applications (China); H. Chen, Naval Armament Academy (China)

714618 A comparison study on SPOT5 image fusion and quality assessment [7146-43] B. Deng, H. Guo, C. Wang, Y. Nie, State Key Lab. of Remote Sensing Science (China) 
714619 A fast checking algorithm of overlay, repetition, and disjoint errors in land spatial data [7146-44]

L. Fang, E.-S. Zhong, M. Yao, Z.-Y. Yu, Institute of Geographical Sciences and Natural Resources Research (China)

\section{SPATIAL MODELS, ALGORITHMS, STATISTICS, AND DATA MINING}

7146 1A Application-oriented model-base system [7146-45]

L. Zhang, Institute of Remote Sensing Applications (China) and Graduate Univ. of Chinese Academy of Sciences (China); Y. Liu, S. Yan, Institute of Remote Sensing Applications (China); L. Yan, Institute of Remote Sensing Applications (China) and Graduate Univ. of Chinese Academy of Sciences (China)

7146 1B An intelligent computational algorithm based on neural network for spatial data mining in adaptability evaluation [7146-46]

Z. Miao, H. XU, Y. Chen, X. Zeng, Wuhan Univ. of Science and Technology (China)

7146 1C Geographic information system data sampling design and implementation [7146-47] C. Jiang, J. Wang, M. Hu, L. Li, Z. Cao, Institute of Geographical Sciences and Natural Resources Research (China)

7146 1D A knowledge-based agent prototype for Chinese address geocoding [7146-48] R. Wei, X. Zhang, L. Ding, H. Ma, Q. Li, Peking Univ. (China)

7146 IE An application of GIS and Bayesian network in studying spatial-causal relations between enterprises and environmental factors [7146-49]

T. Shen, Peking Univ. (China); X. Li, Wuhan Univ. (China); M. Li, Peking Univ. (China)

$7146 \mathrm{IF}$ An automatic rapid annotation placement algorithm of point features based on template [7146-50]

D. Zhang, Zhengzhou Institute of Surveying and Mapping (China) and Xi'an Research Institute of Surveying and Mapping (China); Y. Zhang, Xi'an Research Institute of Surveying and Mapping (China); L. Guo, Zhengzhou Institute of Surveying and Mapping (China)

7146 IG Specialization of China large-scale exchange market based on constrained co-local spatial association rule [7146-51]

X. Zhang, Institute of Geographical Sciences and Natural Resources Research (China) and Tongji Univ. (China); Y. Du, F. Su, Institute of Geographical Sciences and Natural Resources Research (China); W. Wen, Institute of Geographical Sciences and Natural Resources Research (China) and Shandong Univ. of Science and Technology (China)

$71461 \mathrm{H}$ Indirect georeferencing of CBERS-2 imagery with position and attitude constraint conditions [7146-52]

J. Yu, Wuhan Univ. (China) 


\section{Part Two}

714611 Wavelet transform-based edge detection of non-uniform illumination image [7146-53] W. Pei, Dalian Maritime Univ. (China); Y. Y. Zhu, Dalian Fisheries Univ. (China)

7146 1J An algorithm for automatically matching corresponding points on homonymous map features [7146-54]

D. Zhao, Y. Sheng, Nanjing Normal Univ. (China); H. Guo, Zhengzhou Univ. (China)

7146 1K PDEAR model prediction of Protea species in years 2070-2100 [7146-55]

D. Guo, South African National Biodiversity Institute (South Africa); R. Guo, Univ. of Cape Town (South Africa); G. F. Midgley, A. G. Rebelo, South African National Biodiversity Institute (South Africa)

$71461 \mathrm{~L}$ Research on automatic optimization of ground control points in image geometric rectification based on Voronoi diagram [7146-56]

Y. Li, B. Cheng, Ctr. for Earth Observation and Digital Earth (China)

$71461 \mathrm{M}$ Study on the visual algorithm for JPEG-HDR remote sensing image [7146-57]

S. Li, Ctr. for Earth Observation and Digital Earth (China); M. Peng, Anhui Univ. of Technology (China)

7146 iN Using clustering methods in geospatial information systems [7146-58]

X. Wang, Univ. of Calgary (Canada); H. Hamilton, Univ. of Regina (Canada)

714610 Application and key techniques of multi-wavelength lidar [7146-59]

S. Song, P. Li, W. Gong, Y. Ma, J. Li, Wuhan Univ. (China)

7146 IP Toward a 2D vector map with a feature-nodes-based watermarking method [7146-60]

H. Zhang, Y. Li, South China Normal Univ. (China)

$71461 Q$ Geostatistical analysis of soil organic carbon in the farming-pastoral ecotone of Northeast China [7146-61]

C. Y. Ren, Northeast Institute of Geography and Agricultural Ecology (China) and Graduate Univ. of the Chinese Academy of Sciences (China); B. Zhang, Z. M. Wang, K. S. Song,

D. W. Liu, Northeast Institute of Geography and Agricultural Ecology (China); G. Yang, Air Force Aviation Univ. (China)

7146 IR A method for matching Chinese place-name data [7146-62]

Y. Liao, Institute of Geographical Sciences and Natural Resources Research (China) and Graduate Univ. of the Chinese Academy of Sciences (China); J. Wang, Institute of Geographical Sciences and Natural Resources Research (China)

7146 is Study on spatial knowledge representation and reasoning based on Bayesian networks [7146-63]

J. Huang, P. Qi, Y. Wu, Y. Yuan, Wuhan Univ. of Technology (China); F. Ye, National Key Lab.

of Remote Sensing Information and Imagery Analysis (China) 
7146 1T Scale dependence of autocorrelation from a remote sensing perspective [7146-64] S. Yin, Wuhan Univ. (China); X. Chen, Wuhan Univ. (China) and Jiangxi Normal Univ. (China); Z. Yu, Y. Sun, Wuhan Univ. (China); Y. Cheng, Henan General Institute of Surveying and Mapping of Geology (China)

$71461 \mathrm{U} \quad$ BVIFM: a vector model for calculating sunlight shadow effect of terrain on neighboring buildings [7146-65]

F. Zhang, Nanjing Normal Univ. (China); L. Zhang, Nanjing Normal Univ. (China) and Luoyang Institute of Science and Technology (China); G. Lv, Z. Gu, Nanjing Normal Univ. (China)

$71461 \mathrm{~V}$ A new algorithm and its application about distributed snowmelt concentration model [7146-66]

Y. Liu, W. Dai, S. Fang, Xinjiang Univ. (China) and Oasis Ecology Key Lab. of MoE and Xinjiang Uygur Autonomous Region, Xinjiang Univ. (China); Z. Liu, Xinjiang Univ. (China), Oasis Ecology Key Lab. of MoE and Xinjiang Uygur Autonomous Region, Xinjiang Univ. (China), and International Ctr. for Desert Affairs (China)

7146 IW A classification model of Hyperion image base on SAM combined decision tree [7146-67] Z. Wang, Sun Yat-sen Univ. (China) and China Univ. of Geosciences (China); G. Hu, China Univ. of Geosciences (China); Y. Zhou, Sun Yat-sen Univ. (China); X. Liu, China Univ. of Geosciences (China)

7146 1X Automated keys to soil orders based on rule engine [7146-68] L. Qiu, G. Lu, A. Li, Y. Sun, Nanjing Normal Univ. (China)

7146 1Y Parallel optimization of IDW interpolation algorithm on multicore platform [7146-69] X. Guan, H. Wu, Wuhan Univ. (China)

714612 Occlusion detection analysis based on two different DSM models in true orthophoto generation [7146-70]

X. Wang, W. Jiang, F. Bian, Wuhan Univ. (China)

714620 The analysis of land use spatial patterns responded to different geomorphology type: two case studies in Hubei Province, China [7146-71]

Y. He, Wuhan Univ. (China); Y. Liu, Key Lab. of Geographic Information System (China) and Wuhan Univ. (China); H. Zhao, Wuhan Univ. (China) and Jiangxi Normal Univ. (China);

X. Chen, Wuhan Univ. (China)

$714621 \quad$ Study on approaches of spatial data edge matching in GIS [7146-72]

J. Yang, South China Institute of Environmental Sciences (China); X. Yang, Wuhan Univ. (China); K. Lin, D. Yang, K. Zhao, South China Institute of Environmental Sciences (China)

714622 Effectiveness of survey points' density and distribution on vegetation coverage field measurement [7146-73]

Y. J. Yue, L. Gao, Beijing Normal Univ. (China) and Key Lab. of Regional Geography (China); J. A. Wang, Beijing Normal Univ. (China), Key Lab. of Regional Geography (China), and Key Lab. of Environmental Change and Natural Disaster (China); N. Li, Beijing Normal Univ. (China) and Key Lab. of Regional Geography (China) 
714623 Intelligence-based automatic detection and classification of ground collapses using object-based image analysis method: a case study in Paitan of Pearl River delta [7146-74] J. Dou, Guangzhou Institute of Geochemistry (China), Guangzhou Institute of Geography (China), and Graduate Univ. of the Chinese Academy of Sciences (China); X. Zheng, Guangzhou Institute of Geological Survey (China); J. Qian, Guangzhou Institute of Geochemistry (China) and Sun Yat-sen Univ. (China); R. Liu, Q. Wu, Guangzhou Institute of Geography (China)

714624 Automated knowledge extraction based on scientific workflow for satellite remote sensing data [7146-75]

C. Fang, H. Lin, The Chinese Univ. of Hong Kong (Hong Kong, China); J. Zhang, The Chinese Univ. of Hong Kong (Hong Kong, China) and Jianxi Normal Univ. (China)

714625 Spatial statistics and GIS application study in spatial variability analysis of house prices: a case study of Dongguan [7146-76]

Z. Mei, South China Normal Univ. (China) and Sun Yat-sen Univ. (China); Y. Ou, W. Hu, South China Normal Univ. (China)

714626 GIS- and RS-based land use and land cover analysis: case study Rur-Watershed, Germany [7146-77]

G. Waldhoff, G. Bareth, Univ. of Cologne (Germany)

714627 Delimitating central areas of cities based on road density: a case study of Guangzhou City [7146-78]

Q. Zhang, X. Lu, Sun Yat-sen Univ. (China)

\section{DISTRIBUTED AND GRID COMPUTING}

714628 Study on parallel and distributed management of RS data based on spatial database [7146-79]

Y. Chen, Q. Qian, Guangzhou Univ. (China); H. Wu, Ministry of Land and Resources (China); S. Liu, Guangzhou Univ. (China)

714629 A grid framework for integration multi-scale vector and imagery data [7146-80] Y. Fu, South China Normal Univ. (China); M. Chen, Capital Normal Univ. (China); W. Hou, Huazhong Univ. of Science and Technology (China)

7146 2A CoreP2P: a tailored group communication scheme for P2P-grid GIS [7146-81] J. Lin, Y. Fang, B. Chen, X. Lin, Y. Sun, Peking Univ. (China)

$71462 B \quad$ Seamless integration of data services between spatial information Grid and TeraGrid based on broker-based data management model [7146-82]

Y. Zeng, Ctr. for Earth Observation and Digital Earth (China) and Institute of Electronics (China); D. Liu, G. Li, W. Yu, Ctr. for Earth Observation and Digital Earth (China); Z. Huang, Tsinghua Univ. (China); C. Song, Purdue Univ. (United States)

$71462 \mathrm{C}$ The design and implementation of a remote sensing image processing system based on grid middleware [7146-83]

L. Zhong, H. Ma, H. XU, Y. Ding, Wuhan Univ. (China) 
7146 2D GridGIS portal development based on OGCE [7146-84]

Y. Sun, Peking Univ. (China) and Shijiazhuang Railway Institute (China); Y. Fang, B. Chen, Peking Univ. (China); T. A. Rana, Yasar Univ. (Turkey); J. Lin, Peking Univ. (China); X. Li,

Shijiazhuang Railway Institute (China)

$71462 \mathrm{E} \quad$ Design and implementation of a decentralized self-coordinating distributed remote sensing image processing system [7146-85]

R. Wang, Z. Liu, B. Chen, Peking Univ. (China)

$71462 \mathrm{~F} \quad$ A prototype design of parallelizing GIS operations [7146-86]

Z. Xie, L. Wu, China Univ. of Geosciences (China); Z. Ye, China Univ. of Geosciences (China) and Ministry of Education (China)

714626 A QoS- based WSRF service scheduling mechanism in spatial data grid [7146-87] X. WU, Y. Fang, B. Chen, Z. Huang, Peking Univ. (China)

$71462 \mathrm{H} \quad$ A new distributed computing model of mobile spatial information service grid based on mobile agent [7146-88]

G. Tian, Henan Polytechnic Univ. (China); M. Liu, Tongji Univ. (China)

$714621 \quad$ Distributed spatial information integration based on web service [7146-89]

H. Tong, Univ. of New Brunswick (Canada) and Wuhan Univ. (China) and China Univ. of Geosciences (China); Y. Zhang, Univ. of New Brunswick (Canada); Z. Shao, Wuhan Univ. (China)

\section{DEM AND HYDROLOGIC MODELING}

$71462 \mathrm{~J} \quad$ Analysis on characteristics and trend of shoreline evolvement in the Yellow River Estuary [7146-90]

H. Sheng, Z. Tong, J. Wan, East China Univ. of Petroleum (China)

$71462 \mathrm{~K}$ Influence of different spatial sampling schemes on digital elevation models interpolation [7146-91]

X. Yang, Institute of Remote Sensing Applications (China) and Graduate Univ. of Chinese Academy of Sciences (China); W. Cui, Institute of Remote Sensing Applications (China)

$71462 \mathrm{~L}$ The abstraction method research of river network based on catchments' characters deriving digital elevation data [7146-92]

L. Jiang, Institute of Geographical Sciences and Natural Resources Research (China) and Graduate Univ. of Chinese Academy of Sciences (China); Q. Qi, Z. Zhang, J. Han, X. Cheng, Institute of Geographical Sciences and Natural Resources Research (China); A. Zhang, Institute of Geographical Sciences and Natural Resources Research (China) and Graduate Univ. of Chinese Academy of Sciences (China)

$71462 \mathrm{M}$ Spatial distribution of incoming potential solar radiation based on solar analyst model and DEM in Xinjiang, China [7146-93]

J. Li, China Meteorological Administration (China) 
$71462 \mathrm{~N}$ The extraction and quantitative analysis of channel junctions based on DEMs [7146-94] Y. Dong, Nanjing Normal Univ. (China) and Nanjing Univ. of Technology (China); G. Tang, Nanjing Normal Univ. (China); M. Luo, Nanjing Normal Univ. (China) and Institute of Mountain Hazards and Environment (China)

714620 Contour fitting with moving surface considering sample dispersion [7146-95]

M. Li, C. Chen, B. Yuan, Z. Zhu, H. Zhou, Nanjing Univ. of Technology (China)

7146 2P A new automatic matching method of SAR data for DEM extraction [7146-96]

X. X. Ou, S. Ning, Wuhan Univ. (China)

$71462 Q \quad$ Research on the slope-landscape TUPU in northern Shaanxi Loess Plateau [7146-97]

F. Li, G. Tang, Nanjing Normal Univ. (China); Y. Dong, Nanjing Univ. of Technology (China)

$71462 R \quad$ Study on high-resolution representation of terraces in Shanxi Loess Plateau area [7146-98] W. Zhao, Nanjing Normal Univ. (China) and Hefei Univ. of Technology (China); G. Tang, Nanjing Normal Univ. (China); L. Ma, Hefei Univ. of Technology (China)

714625 A problem-oriented approach for DEM data management and manipulation [7146-100] F. Huang, Y. Fang, B. Chen, Peking Univ. (China)

$71462 \mathrm{~T}$ The algorithm of creating contour lines based on DEM [7146-101]

L. Tang, A. Xu, L. Fang, Zhejiang Forestry Univ. (China)

$71462 \mathrm{U}$ Statistical texture for contour interval choice of 1:50,000 DEMs [7146-102]

M. Luo, Nanjing Normal Univ. (China) and Institute of Mountain Hazards and Environment (China); G. Tang, S. Yan, Y. Dong, Nanjing Normal Univ. (China)

$71462 \mathrm{~V} \quad$ Mapping color relief shading based on DEM [7146-103]

T. Cao, China Siwei Surveying and Mapping Technology Corp. (China); Z. He, L. Xu, Wuhan Univ. (China)

Author Index 


\title{
Symposium Committees
}

\author{
Honorary Chairs
}

Guanhua Xu, Academician, Chinese Academy of Sciences (China)

Deren Li, Academician, Chinese Academy of Sciences, Wuhan

University (China)

Conference Chairs

Xia Li, School of Geography and Planning, Sun Yat-sen University (China)

Lin Liu, Department of Geography, University of Cincinnati (United States)

Proceedings Editor-In-Chief

Lin Liu, Department of Geography, University of Cincinnati (United States)

Xia Li, School of Geography and Planning, Sun Yat-sen University (China)

International Steering Committee

M.F. Goodchild, University of California, Santa Barbara (USA)

Michael Batty, University College London (United Kingdom)

John R. Townshend, University of Maryland, College Park (USA)

Robert McMaster, University of Minnesota (USA)

Harvey Miller, University of Utah (USA)

Nina Lam, Louisiana State University (USA)

Mark Gahegan, Penn State University (USA)

Qingxi Tong, Institute of Remote Sensing Application, Chinese Academy of Sciences (China)

Xiaowen Li, Beijing Normal University (China) and Institute of Remote Sensing Application, Chinese Academy of Sciences (China)

Gar-on Yeh, University of Hong Kong (China)

Jiyuan Liu, Institute of Geographical Sciences and Natural Resources Research, Chinese Academy of Sciences (China)

Jun Chen, National Center for Geomatics (China)

Yimin Jin, National Remote Sensing Center (China)

Lizhong Yu, East China Normal University (China)

Peijun Shi, Beijing Normal University (China)

Ke Liao, Institute of Geographical Sciences and Natural Resources Research, Chinese Academy of Sciences (China) 
Jicheng Cheng, Beijing University (China)

Xingyuan Huang, Nanjing University (China)

Jigang Bao, Sun Yat-sen University (China)

Technical Committee

Fang Qiu, Chair, University of Texas, Dallas (USA)

Xiaoxiang Chen, Chair, Sun Yat-sen University (China)

Lin Liu, Chair, Department of Geography, University of Cincinnati (United States)

Bingkai Ye, Chair, Guangdong Association of Remote Sensing and Geographic Information Systems (China)

Shuming Bao, University of Michigan (USA)

Richard Beck, University of Cincinnati (USA)

Ling Bian, State University of New York at Buffalo (USA)

Ruru Deng, Sun Yat-sen University (China)

Yongjiu Dai, Beijing Normal University (China)

John Eck, University of Cincinnati (USA)

Robert Frohn, University of Cincinnati (USA)

Huili Gong, Capital Normal University (China)

Jianhua Gong, Institute of Remote Sensing Applications, Chinese Academy of Sciences (China)

Jianya Gong, Wuhan University (China)

Peng Gong, Institute of Remote Sensing Applications, Chinese Academy of Sciences (China), University of California, Berkeley (USA), and Nanjing University (China)

Mei-Po Kwan, Ohio State University (USA)

Yong Lao, California State University, Monterey Bay (USA)

Bin Li, Central Michigan University (USA)

Jing Li, Beijing Normal University (China)

Qi Li, Peking University (China)

Zhilin Li, Hong Kong Polytechnic University (China)

Shunlin Liang, University of Maryland, College Park (USA)

Hui Lin, Chinese University of Hong Kong (China)

Yaolin Liu, Wuhan University (China)

Guonian Lu, Nanjing Normal University (China)

Mingming Lu, University of Cincinnati (USA)

Liqiu Meng, Technical University of Munich (Germany)

Jiaguo Qi, University of Michigan (USA)

Qingwen Qi, Institute of Geographical Science and Resources

Research, Chinese Academy of Sciences (China)

Qiming Qing, Peking University (China)

Yun Shao, Institute of Remote Sensing Applications, Chinese Academy of Sciences (China)

Shih-Lung Shaw, University of Tennessee (USA)

Wenzhong Shi, Hong Kong Polytechnic University (China)

Daniel Dianzhi Sui, Texas A\&M University (USA) 
Xinming Tang, Chinese Academy of Surveying and Mapping (China) Vicent Tao, Microsoft Corporation (USA)

Susanna Tong, University of Cincinnati (USA)

James Uber, University of Cincinnati (USA)

Yingjie Wang, Institute of Geographical Science and Resources

Research, Chinese Academy of Sciences (China)

Jingfeng Wang, Institute of Geographical Science and Resources Research, Chinese Academy of Sciences (China)

Fahui Wang, Louisiana State University (USA)

Le Wang, State University of New York at Buffalo (USA)

Xinhao Wang, University of Cincinnati (USA)

Lixing Wu University of Mining \& Technology (China)

David Wong, George Mason University (USA)

Lun Wu, Beijing University (China)

Bing Xu, University of Utah (USA)

Qingnian Zhang, Sun Yat-sen University (China)

Xinchang Zhang, School of Geography and Planning, Sun Yat-sen University (China)

Chenghu Zhou, Institute of Geographical Science and Resources Research, Chinese Academy of Sciences (China)

Qiming Zhou, Hong Kong Baptist University (China)

A-Xing Zhu, University of Wisconsin, Madison (USA)

Local Organizing Committee

Xinchang Zhang, Chair, School of Geography and Planning, Sun Yat-sen University (China)

Linyuan Xia, Chair, Sun Yat-sen University (China)

Kai Liu, Guangzhou Institute of Geography, Guangdong Academy of Sciences (China)

Qingnian Zhang, Sun Yat-sen University (China)

Zhijian He, Sun Yat-sen University (China)

Guoming Du, Sun Yat-sen University (China)

Haiyan Tao, Sun Yat-sen University (China)

Linbing Ma, Sun Yat-sen University (China)

Holly Arnold, University of Cincinnati (USA) 
Downloaded From: https://www.spiedigitallibrary.org/conference-proceedings-of-spie on 25 Apr 2023

Terms of Use: https://www.spiedigitallibrary.org/terms-of-use 


\section{Introduction}

All papers included in this volume are selected from the 16th International Conference on Geolnformatics and the Joint Conference on GIS and Built Environment organized by Sun Yat-sen University and the University of Cincinnati and held 28-29 June 2008 in Guangzhou, China. The Geoinformatics conference series was initiated by the International Association of Chinese Professionals in Geographic Information Sciences (CPGIS) in 1992. The Joint Conference on GIS and Built Environment is a new conference series initiated by Sun Yat-sen University and the University of Cincinnati.

The central theme of the combined conference is GIS, Built Environment, and Geo-simulation. The main topics included geo-simulation and virtual GIS environments, the built environment and its dynamics, the monitoring and assessment of natural resources and environments, advanced spatial data models and analyses, and classification of remote sensing images.

This combined conference provided a unique forum for exchanging ideas and knowledge on geo-information sciences between GIS professionals worldwide. This year's Geolnformatics conference is the largest ever. Over 800 participants came from 15 countries and regions, including the United States, the United Kingdom, Canada, Germany, Australia, South Africa, Turkey, Singapore, Malaysia, Thailand, United Arab Emirates, Mainland China, Hong Kong, Macau, and Taiwan. The organizers received more than 900 abstracts, and nearly 600 full papers. The conference program consists of 212 oral presentations and over 300 posters.

All papers in this volume are selected through a rigorous peer-review process. We believe that you will find these papers useful.

Finally, we would like to thank all authors and reviewers for their contributions to this volume.

Lin Liu and Xia Li Conference Co-Chairs Editors-In-Chief 
Downloaded From: https://www.spiedigitallibrary.org/conference-proceedings-of-spie on 25 Apr 2023

Terms of Use: https://www.spiedigitallibrary.org/terms-of-use 